\title{
Using Time-Series Analysis to Assess the Extent of Climate Variability and Climate Change in Bayelsa State, Nigeria
}

\section{*AGBONAYE, AI; IZINYON, OC}

Department of Civil Engineering, University of Benin, Benin City, Nigeria

*Corresponding Author Email: augustine.agbonaye@uniben.edu

\begin{abstract}
Time series analysis is a useful statistical tool in the assessment of climate variability and climate change. This study applied a time series analysis to rainfall and temperature data in the Bayelsa State of Nigeria. Since NIMET has only one gauging station in the state, Climate Research (CRU $0.5 \times 0.5)$ gridded data for 28 locations from 1956 to 2016 were used. They were sorted, validated with NiMet data, and utilized for analyses of various time series techniques such as Mann-Kendal, Spearman's Rho, Linear Regression, Thei-Sen Slope Cumulative sum, Cumulative Deviation, Rank Sum, Student's (t-test) and spectral analysis. The results obtained revealed that there had been increasing temperature and abrupt climatic changes in the state, especially in the 1976-1985 decade, with 1980 as the most probable year of abrupt change. The hottest decade was 1986-1995, with an average temperature change of $0.14856{ }^{\circ} \mathrm{C}$ /decade, while the coolest decade was $1976-1985$ with an average Temperature change of $-0.01723{ }^{\circ} \mathrm{C} / \mathrm{dec}$ ade. Also, there had been some changes in rainfall, with the wettest decade occurring in 1986-1995 with an average rainfall change of 61 $\mathrm{mm} /$ decade, while the driest decade occurred in 1976-1985 with an average rainfall change of $14.08 \mathrm{~mm} / \mathrm{decade}$. The output of spectral analysis showed that the most Significant Periodicity for Rainfall and Temperature was 15 years. The result further revealed that there was high rainfall variability with a coefficient of variability of $62.74 \%$. These rainfall fluctuations have implications for coastal flooding, quality, and quantity of available groundwater in the state. These results are useful to planners and policymakers in creating awareness of climate change's impact on rainfall in the study area
\end{abstract}

\section{DOI:https://dx.doi.org/10.4314/jasem.v25i10.9}

Copyright: Copyright (C) 2021 Agbonaye and Izinyon. This is an open access article distributed under the Creative Commons Attribution License (CCL), which permits unrestricted use, distribution, and reproduction in any medium, provided the original work is properly cited.

Dates: Received: 22 August 2021; Revised: 17 September 2021; Accepted: 06 October 2021

Keywords: climate variability, Climate change, Time Series, Trend, Periodicity,

The vulnerability of the Nigerian coastline to sea level rise is particularly exacerbated by its low lying, densely populated nature, leading to high human activities and oil pollution caused by exploration in some areas. Rainfall, thermal expansion of water in ocean leading to wave heights, increase the risk of coastal flooding, which result in displacement of households, infrastructure loss, accelerated coastal erosion, salinization of surface and coastal aquifer causing declining water quality, an outbreak of waterborne diseases, and diminishing food security. These have been attributed to the impacts of climate change. The determination of the degree of variability and the magnitudes of climate change which have not gained much prominence are crucial for planning adaptation and mitigation measures. The Niger Delta region, where Bayelsa state is part of, is located within the coastal areas that are most vulnerable to climate change occasioned by a change in temperature, precipitation, and more frequent flooding. This is responsible for the ravaging issue of rising sea levels and wave heights, including accelerated coastal erosion. In addition, coastal communities also face numerous socio-economic challenges that promote their vulnerability to climate change and their ability to respond to changes in severe events such as storms. Examples of such socio-economic challenges include transitory populations, physical isolation, poor-quality housing, and low income (Zsamboky et al., 2011). According to projections, temperatures will continue to rise, and increasing sea levels will pose a threat to coastal populations' survival. Rain-fed agricultural and hydropower outages are already being impacted by less rainfall, resulting in severe reductions in industrial production. Flooding will become more common as a result of climate change, particularly in developing countries like Nigeria (Ekpenyong and Tonbra, 2015). One of the challenges posed by climate change/climate variability is ascertainment, identification, and quantification of trends in rainfall and their implications on river flows to assist in formulating adaptation measures through appropriate strategies for water resources management. Preparation and formulation of appropriate policies to mitigate the impact of climate change and variability in the region require a holistic understanding of the climatic 
dynamics, both temporal and spatially. Sadly, there is a scarcity of data on current rates of climate variability, changes in coastal geomorphology, and socioeconomic developments in Africa (Hinkel et al., 2012). This has a lot of ramifications for the creation of models that can be used to mitigate climate change and adapt to it. Furthermore, the majority of the information available on the region was either focused on flooding or sea-level rise. However, little research has been done on how the climate in Nigeria's Coastal Region, particularly Bayelsa State, is changing (Olasupo et al., 2017). However, information on the use of time-series analysis is scarce, hence, the objective of this paper is to employ time-series analysis to assess the extent of climate variability and climate change in Bayelsa State, Nigeria.

Study Area and Data Used: Bayelsa State is situated between the latitudes of 040 15' North and 05o 23' South, as well as the longitudes of 050 22' West and 06o 45' East. It is bordered on the north by Delta State, on the east by Rivers State, and on the west and south by the Atlantic Ocean. . It is in the core oil-rich Niger Delta region, South-South Nigeria. Brass, Ekeremor, Kolokuma/Opokuma, Nembe, Ogbia, Sagbama, Southern Ijaw, and Yenagoa are the eight Local Government Areas that make up the state. The state is 21,100 square kilometers in size, with Yenagoa as its capital. Bayelsa State is a tropical rain forest, with water covering more than three-quarters of the land and a somewhat low land running from Ekeremor to Nembe. With a tangle of meandering rivers and mangrove swamps, the site is almost entirely below sea level (Ekpenyong and Tonbra, 2015). The principal rivers of the South, such as the San Bartholomew, Brass Nun, Ramos, Santa Barbara, St. Nicholas, Sangbana, Fishtown, Ikebiri Creek, Middleton, Digatoro Streams, Pennington, and Dobo, all run into the Atlantic Ocean. Bayelsa State is situated in a riverine and estuarine environment. Many settlements are nearly (and in some cases completely) encircled by water, rendering them road inaccessible.

The mangrove forest distinguishes the vegetation. It features a thick forest in the north, as well as agricultural fields for the production of numerous food and cash crops. Bayelsa has a population of 1,704,515 people according to the 2006 census, with a predicted population of 263346 people in 2021. (NPC, 2021)

Data Collection: Climate Research Unit $0.5^{\circ}$ latitude by $0.5^{\circ}$ longitude (CRU $0.5 \times 0.5$ ) gridded monthly climatic data for two climatic periods ((1956- 1986 and 1987-2016) for twenty -three locations in the state, downloaded from the internet, were sorted into annual rainfall series and validated with the Nigerian Meteorological Agency (NiMet) data. The performance of these data was assessed using a goodness of fit measure such as the Coefficient of Determination ( $R 2$ ). When the value of $R 2$ is within the range of $0.75<\mathrm{R}^{2}<1$, the result is extremely good. The lack of fully accurate data hinders climate trend analysis, adding to the challenges of associated relevant study; thus, data validation was performed. The lack of fully reliable data hinders climate trend analysis, adding to the challenges associated with relevant study; thus, data validation was performed.

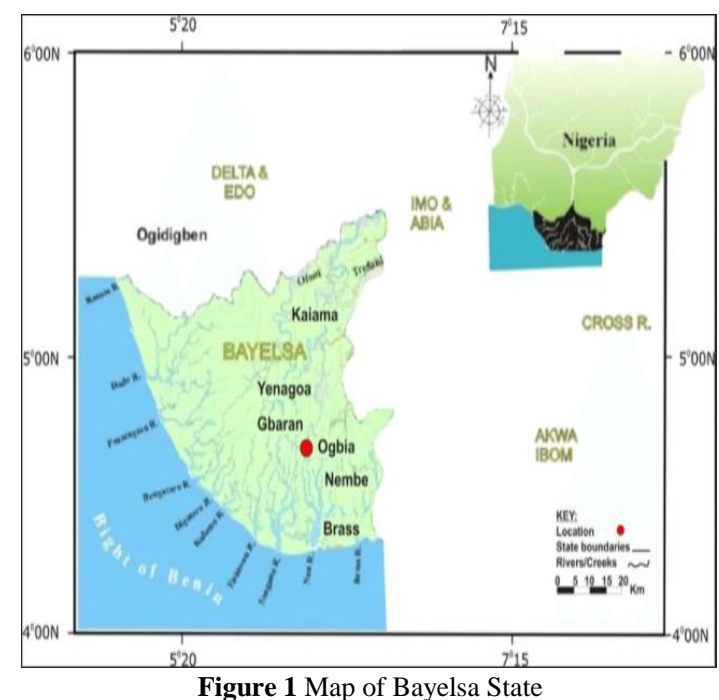

Preliminary Data Analysis: The XLSTAT program was used to implement descriptive statistics of yearly rainfall time series, including minimum, maximum, and range, mean, and standard deviation, and variance, standard error of the mean, kurtosis, and skewness, as well as associated standard errors computations. . These figures aid in gaining a rough understanding of the dispersion and distribution of the mean annual rainfall data set.

To evaluate whether the dataset could be characterized by a normal distribution or not, the Shapiro Wilk Test (SWT), D'Agostino-Pearson Test, and Skewness Test were used to compute how probable an underlying random variable was to be normally distributed. As a result, data screening, outlier detection, description, assumption checking, and describing variances among sub-populations became possible.

Homogeneity tests were performed to help assess trend dependability and identify appropriate sub-periods for the investigation. XLSTAT software was used to implement the following homogeneity tests: Pettit's Test, Standard Normal Homogeneity Test (SNHT), Buishand's Test, and Von Neumann Ratio. The extent 
to which observations in a series separated by different time differences tend to be similar is measured by serial correlation coefficients. Before the application of the Mann-Kendall (MK) test, the time series must be free of serial correlation, which can mislead the actual result of the trends (Yue et al., 2002). Consequently, the serial correlation was checked by Durbin Watson' S Test were implemented using XLSTAT software.

The distribution of the residuals is assumed to be constant across the plot in linear regression. (Homoscedastic). To confirm this Breusch-Pagan \& White heteroscedasticity test was implemented by using XLSTAT Software. This was to ensure that Linear Regression Model can be safely used for further analysis The time series must be devoid of serial correlation before applying the Mann-Kendall (MK) test, as this can mislead the true outcome of the trends (Yue et al., 2002).

We carried out a full-time series analysis on the data when we were happy with the determined data attributes.

Data Analysis: The following time series was used to discover a trend in the yearly rainfall data: MannKendal, Spearman's Rho, and Linear Regression test. Thei-Sen Slope test was used to determine the magnitude of the trend analysis. The Distribution-free CUSUM (cumulative sum) test, Cumulative Deviation, and the Worsley Likelihood test were used for Rainfall abrupt change (Step Jump) detection. Rank Sum \& Student's (t-test) were used to check for differences between means of two climatic periods using TREND Software. Finally, Periodicity (cycles) were determined by the spectral analysis were implemented using XLSTAT. This study revealed recurrent cycles of various lengths in a time series that appeared to be random noise at first. A periodogram is a graph that shows the amplitude (or power) of each cycle vs its frequency (or periods).

The Mann-Kendall (MK): Spatial annual rainfall time series were examined for the presence of trends by using MK, a non -parametric test (Machiwal and Jha. 2012). It tests statistic $Z$ was calculated as:

$Z_{s}=\left\{\begin{array}{cl}\frac{S-1}{\sqrt{V(S)},} & S>0 \\ 0 & S=0 \\ \frac{s+1}{\sqrt{V(S)},} & S<0 .\end{array}\right.$
$Z_{s}$ is the standard normal test statistic in cases where the sample size $n>10$.

The variance $V(S)$ of statistic $S$ obtained as:

$$
V(S)=\frac{n(n-1)(2 n+5)-\sum_{k=1}^{m}\left(t_{k}-1\right)\left(2 t_{k}+5\right)}{18}
$$

Where m signifies the number of ties for the value and denotes the number of connected groups. A tied group is a collection of samples with the same value.

For $\alpha=0.1, Z_{(\alpha / 2)}=Z_{0.05=1.645}$

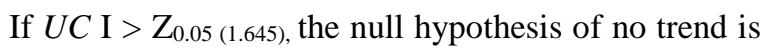
rejected at the $\alpha$ significance level

Theil-Sen Analysis: Theil-Sen estimator is used in quantifying the magnitude of trends. It has been widely used in analysi-ng hydrological time series data. TheilSen's estimator is computed as (Machiwal and Jha. 2012);

$$
Q_{\text {med }}=\operatorname{median}(Q) \text {, }
$$

$$
Q=\frac{x_{j}-x_{i}}{j-i}, i<j,
$$

Where $\mathrm{Q}_{\text {med }}=$ slope between data points $x \mathrm{i}$ and $x \mathrm{j}, x \mathrm{i}=$ data measurement at time $i, x \mathrm{j}=$ data measurement at time $j$; and $j=$ time after time $i$; respectively.

Spearman's Rho Test for Trend $\left(\mathrm{R}_{\mathrm{S}}\right)$ (McCuen, 2003). This is a nonparametric and Rank-based, alternative to the Pearson R, which is a parametric test

The hypotheses for a direct trend (one-sided) are:

H0: The values of the series represent a sequence of $n$ independent events.

HA: The values show a positive correlation

For the two series $x_{i}$ and $y_{i}$, the rank of each item within each series separately is determined, with a rank of 1 for the smallest value and a rank of $\mathrm{n}$ for the largest value. The ranks are represented by $r_{x i}$ and $r_{y i}$, with the I corresponding to the ith magnitude. Using the ranks for the paired values $r_{x i}$ and $r_{y i}$, the value of the Spearman coefficient RS is computed using: 


$$
R_{s}=1-\frac{6 \sum_{i=1}^{N}\left(r_{\text {II }}-r_{y i}\right)^{2}}{n^{3}-n}
$$

For sample sizes greater than ten, the following statistic can be used to test the above hypotheses:

$$
t=\frac{R_{z}}{\left[\left(1-R_{s}^{2}\right) /(n-2)\right]^{0.5}}
$$

Where $t$ follows a Student's $\mathrm{t}$ distribution with $n-2$ degrees of freedom. For a one-sided test for a direct trend, the null hypothesis is rejected when the computed $t$ is greater than the critical $t_{\alpha}$ for $n-2$ degrees of freedom

Linear Regression Test: The test statistic, $\mathrm{T}_{\mathrm{O}}$ follows a $t$ distribution with (n-2) degrees of freedom, where $n$ is the total number of observations. This study revealed recurrent cycles of various lengths in a time series that appeared to be random noise at first. A periodogram is a graph that shows the amplitude (or power) of each cycle vs its frequency (or periods). The null hypothesis, Ho, is accepted if the test statistic's estimated value is such that:

The regression formula is as follows:

$y=a+b x$

The regression gradient is estimated by:

$b=\frac{\sum_{i=1}^{n}\left(x_{i}-\bar{x}\right)\left(y_{i}-\bar{y}\right)}{\sum_{i=1}^{n}\left(x_{i}-\bar{x}\right)^{2}}$

And the intercept is estimated as:

$a=y-b x$

The test statistic is a $t$ statistic ( $\mathrm{t}$ ), which is described by the equation:

$\mathrm{T}_{\mathrm{O}}=\mathrm{b}_{1} / \mathrm{SE}$

Where b1 is the sample regression line's slope and SE is the slope's standard error.

$$
\begin{aligned}
& \mathrm{SE}=\mathrm{s}_{\mathrm{b} 1}=\operatorname{sqrt}\left[\Sigma\left(\mathrm{y}_{\mathrm{i}}-\hat{\mathrm{y}}_{\mathrm{i}}\right)^{2} /(\mathrm{n}-2)\right] / \operatorname{sqrt}\left[\Sigma\left(\mathrm{x}_{\mathrm{i}}-\mathrm{x}\right)^{2}\right] \\
& (12) \\
& -t_{\alpha / 2, n-2}<T_{0}<t_{\alpha / 2, n-2}
\end{aligned}
$$

Where $t_{\alpha / 2, n-2 \text { and }}-t_{\alpha / 2, n-2}$ are the critical values of the two-sided hypothesis' crucial values. is the significance level, and is the percentile of the distribution corresponding to a cumulative probability of

Distribution Free Cumulative Sum (CUSUM) Test: Distribution free CUSUM test was used to identify the change point in a series of data This approach (Chiew and Siriwardena 2005) determined whether the means in two parts of a record were time series data (x1, x2, $\mathrm{x} 3, \ldots \mathrm{xn})$. The test statistic is:

$V_{k}=\sum^{k} \operatorname{sgn}\left(x_{i}-x_{\text {memn }}\right) k=1,2,3, \ldots \ldots h$.

Where $\operatorname{sgn}(\mathrm{x})=1$ for $\mathrm{x}>0$

$\operatorname{sgn}(\mathrm{x})=0$ for $\mathrm{x}=0$

$\operatorname{sgn}(\mathrm{x})=-1$ for $\mathrm{x}<0$

$\mathrm{X}_{\text {medium }}$ is the median value of the $\mathrm{x}_{\mathrm{i}}$ data set.

The distribution of $\mathrm{V}_{\mathrm{k}}$ follows the KolmogorovSmirnov two-sample statistic $\left(\mathrm{KS}=(2 / \mathrm{n}) \max \left|\mathrm{V}_{\mathrm{k}}\right|\right)$ given by: CUMSUM values - Cumulative sum series

Cumulative Deviation Test: This test is performed to find out if there has been a change in the mean. . The cumulative deviations from the mean are determined using the following formula:

$S_{o} .=0 S_{k}=\sum_{i=1}^{k}\left(x_{i}-X\right) k=1,2,3, \ldots . ., n .$.

and by dividing the $\mathrm{Sk}^{*}$ values by the standard deviation, the rescaled adjusted partial sums are obtained:

$\mathrm{S}_{\mathrm{k}}^{* *}=\mathrm{S}_{\mathrm{k}}^{*} / \mathrm{D}$

$D_{x}^{2}=\sum_{i=1}^{n} \frac{\left(x_{i}-x\right)^{2}}{n}$

The test statistic Q (sensitive to departure from homogeneity) is:

$\mathrm{Q}=\max \left|\mathrm{S}_{\mathrm{k}} * *\right|$

Each year's value is calculated, with the highest value representing the year's changing point. Sk * with a negative value indicates that the mean of the latter section of the record is greater than the earlier part, and vice versa.

The critical value $=Q / \sqrt{ }$ ( $n$ ) at $95 \%$ confidence interval. The following formula is used to compute the cumulative deviations from the mean: 


$$
S_{o} .=0 S_{k}=\sum_{i=1}^{k}\left(x_{i}-X\right) k=1,2,3, \ldots . ., n . .
$$

and by dividing the $\mathrm{Sk}^{*}$ values by the standard deviation, the rescaled adjusted partial sums are obtained:

$$
\begin{aligned}
& \mathrm{S}_{\mathrm{k}}{ }^{* *}=\mathrm{S}_{\mathrm{k}}{ }^{*} / \mathrm{D} \\
& D_{x}{ }^{2}=\sum_{i=1}^{n} \frac{\left(x_{i}-x\right)^{2}}{n}
\end{aligned}
$$

The test statistic Q (sensitive to departure from homogeneity) is:

$\mathrm{Q}=\max \left|\mathrm{S}_{\mathrm{k}} * *\right|$

Each year's value is calculated, with the highest value representing the year's changing point. Sk $*$ with a negative value indicates that the mean of the latter section of the record is greater than the earlier part, and vice versa.

he critical value $=\mathrm{Q} / \sqrt{ }(\mathrm{n})$ at $95 \%$ confidence interval

Worsley Likelihood: This method (Mundia 2014) determines whether the means of two segments of a recorded data set differ considerably (for an unknown period of change)

$W=\frac{(n-2)^{0.5} V}{\left(1-V^{2}\right)^{0.5}}$

$$
\text { where } V \max \left|Z_{k} * *\right|
$$

A negative $\mathrm{W}$ number implies that the mean of the latter half of the record is greater than the earlier part, and vice versa.

Mann Whitney U Test (Wilcoxon Rank Sum Test): The Wilcoxon Rank Sum Test is used to determine whether two samples came from the same population (i.e., that the two populations have the same shape). The following are the null and two-sided study hypotheses for the nonparametric test: In the case of a two-tailed statistical test,

Null hypothesis: $H_{o}: \mu_{1}=\mu_{2}$, i.e. the two populations mean are equal

Alternative hypothesis: $H_{a}: \mu_{1 \neq \mu_{2}}$, i.e. the two populations mean are not equal

The decision rule for an $\alpha$-level test: For large sample: Reject $H_{o}$ in favour of $H_{a}$ According to Woolson and Clarke (2002) if

$$
\begin{aligned}
& \text { Zobs }=\mathrm{T}_{1-0.5} \mathrm{n}_{1}\left(\mathrm{n}_{1} \cdot \mathrm{n}_{2}\left(\mathrm{n}_{1}+\mathrm{n}_{2}+1\right)\right) / / \mathrm{sqr}\left(\mathrm{n}_{1} \cdot \mathrm{n}_{2}\left(\mathrm{n}_{1}+\mathrm{n}_{2}+1\right)\right) / 12 \\
& >\mathrm{Z}_{1-\alpha / 2} \\
& \text { (23) } \\
& \text { or if } \left.\quad Z_{\text {obs }}=\mathrm{T}_{1-0.5} \quad \mathrm{n}_{1} \quad\left(\mathrm{n}_{1}+\mathrm{n}_{2}+1\right)\right) / / / \mathrm{sqr} \quad\left(\mathrm{n}_{1} \cdot \mathrm{n}_{2}\right. \\
& \left.\left(\mathrm{n}_{1}+\mathrm{n}_{2}+1\right)\right) / 12 \quad<-\mathrm{Z}_{1-\alpha / 2}
\end{aligned}
$$

Where $\mathrm{n} 1$ denotes the sample 1 number of subjects and $\mathrm{n} 2$ denotes the sample 2 number of subjects. $\mathrm{n}=\mathrm{n} 1+\mathrm{n} 2$ is the total number of subjects.

Student's t-Test: This test is used to check the null hypothesis of whether equal means in two different periods are different (Mu et al., 2007). The test is based on the assumption that the data is regularly distributed. The following is how the relationship is expressed:

$$
t=\frac{(x y)}{S \sqrt{\frac{1}{n}+\frac{1}{m}}}
$$

where $x$. and,y. in equation 24 are the first and secondperiod means, $\mathrm{m}$ and $\mathrm{n}$ are the first and second-period numbers of observations, and $\mathrm{S}$ is the sample standard deviation (of the entire $\mathrm{m}$ and $\mathrm{n}$ observations). The $\mathrm{P}$ value is calculated using the $\mathrm{t}$ statistic test statistic and the degrees of freedom. The likelihood that a $t$ statistic with 59 degrees of freedom is more extreme than 2.29 is given by the P-value. "More extreme" indicates greater than 2.29 or less than -2.29 in this two-tailed test.

The null hypothesis, $H_{0}$, is accepted if the calculated value of the test statistic is such that:

$$
-t_{\alpha / 2, n-2}<T_{0}<t_{\alpha / 2, n-2}
$$

where $t_{\alpha / 2, n-2}$ and $-t_{\alpha / 2, n-2}$ are the critical values for the two-sided hypothesis. $t_{\alpha / 2, n-2}$ is the percentile of the $t$ distribution corresponding to a cumulative probability of $(1-\alpha / 2)$, and $\alpha$ is the significance level.

\section{RESULTS AND DISCUSSIONS}

Preliminary analysis: Results of the analysis carried out are presented in Table 1 and Table 2. Validity analysis: The results of validity analysis indicate that $\mathrm{R}^{2}$ was 0.935 and. 0.954 for rainfall and temperature, respectively. This performance rating of $\mathrm{R}^{2}$ is very good as $0.75<\mathrm{R}^{2} \leq 1$. Hence, the CRU data obtained is very reliable and could be safely used for further analysis in this study 
The Descriptive statistics of mean annual rainfall (1956- 1986 and 1987-2016) are presented in Table 2. The Table 2 was obtained by use of XL Statistic software. The table shows that the mean annual rainfall varies from $276.182 \mathrm{~mm}$ in (Second climatic period) to $\mathrm{mm} 274.493$ in (First climatic period). The standard deviation varied from $158.524 \mathrm{~mm}$ to $149.599 \mathrm{~mm}$, while the skewness and kurtosis varied from -0.015 to -0.087 and -1.502 to -1.150 , respectively. These skewness and kurtosis values indicate that the rainfall series is close to being a normal distribution.

Three common normality tests were carried out, namely Shapiro Wilk Test (SWT), D`AgostinoPearson Test, and Skewness Test. The outcomes are shown in Table 3

Table .1: Comparison between NIMET and CRU data for Rainfall and Temperature

\begin{tabular}{|c|c|c|c|c|c|c|c|c|c|c|c|c|c|}
\hline $\mathrm{S} / \mathrm{N}$ & & $\mathrm{R}^{2}$ & & $\operatorname{Adj~R~}{ }^{2}$ & & $\mathrm{~K}$ tau & & RSR & & MAPE & & $\mathrm{Cp}$ & \\
\hline 1 & Rainfall & 0.931 & V.good & 0.907 & V.good & 0.782 & V.good & 0.302 & V.good & 19.2 & Good & 2.8 & $\mathrm{OK}$ \\
\hline 2 & Temp & 0.954 & V.good & 0.949 & V.good & 0.891 & V.good & 0.225 & V.good & 0.588 & $\mathrm{H}$ & 2 & $\mathrm{OK}$ \\
\hline
\end{tabular}

Table 2: Descriptive statistics of mean annual rainfall (1956- 1986 and 1987-2016),

\begin{tabular}{|c|c|c|c|c|c|c|c|c|c|c|}
\hline $\begin{array}{l}\text { Climatic } \\
\text { Type }\end{array}$ & $\begin{array}{l}\text { Climatic } \\
\text { period }\end{array}$ & $\begin{array}{l}\text { Mean } \\
\text { mm }\end{array}$ & $\begin{array}{l}\mathrm{SD} \\
\mathrm{mm}\end{array}$ & $\begin{array}{l}\text { Min } \\
\text { mm }\end{array}$ & $\begin{array}{l}\text { Max } \\
\text { mm }\end{array}$ & $\begin{array}{l}\text { Range } \\
\mathrm{mm} /\end{array}$ & $\begin{array}{l}\text { Sum } \\
(\mathrm{mm})\end{array}$ & $\% \mathrm{CV}$ & Skewness & Kurtosis \\
\hline Rainfall & NIMET & 237.1409 & 139.39 & 33.27 & 428.725 & 395.45 & 2608.55 & 58.78 & -0.2039 & -1.557 \\
\hline Rainfall & CRU & 256.1748 & 160.73 & 45.39 & 464.289 & 418.903 & 3074.098 & 62.74 & 0.067378 & -1.513 \\
\hline Temp & NIMET & 26.66 & 0.93 & 25.4 & 28 & 2.6 & 293.3 & 3.49 & -0.0314 & -1.363 \\
\hline Temp & CRU & 30.39 & 1.3242 & 28.267 & 32.046 & 3.7786 & 364.717 & 4.36 & -0.43492 & -1.3123 \\
\hline Rainfall & First & 274.493 & 149.599 & 55.805 & 475.693 & 419.889 & 3019.42 & 54.500 & -0.015 & -1.334 \\
\hline Rainfall & Second & 276.182 & 158.524 & 52.279 & 485.564 & 433.285 & 3038.00 & 57.398 & -0.087 & -1.472 \\
\hline Temp & First & 30.081 & 1.324 & 31.817 & 30.081 & 3'645 & 330.89 & 4.401 & -0.171 & -1.150 \\
\hline Temp & Second & 30.583 & 1.422 & 28.362 & 32.274 & 3.913 & 336.413 & 4.650 & -0.392 & -1.502 \\
\hline
\end{tabular}

Table: 3 Result of Test for Normality of Spatial Rainfall and Temperature Data

\begin{tabular}{|c|c|c|c|c|c|c|c|c|c|c|}
\hline \multicolumn{4}{|c|}{ Shapiro Wilk Test (Swt) } & \multicolumn{4}{|c|}{ D'Agostino-Pearson Test } & \multicolumn{3}{|c|}{ Skewness Test $(-0.59<S<0.59)$} \\
\hline W-STAT & P-value & Alpha & normal & DA STAT & P-value & alpha & normal & $\mathrm{S}$ & alpha & Normality \\
\hline 0.9119 & 0.2570 & 0.05 & YES & 1.9496 & 0.3773 & 0.05 & YES & 0.06737 & 0.05 & YES for Rainfall \\
\hline 0.9196 & 0.3158 & 0.05 & YES & 2.5974 & 0.2729 & 0.05 & YES & -0.4349 & 0.05 & YES, for Temp \\
\hline
\end{tabular}

Hypotheses: Null hypothesis =Ho: The data follow a normal distribution: Alternate hypothesis =Hi: The Data do not follow a normal distribution

Table 4 Results of Homogeneity Tests

\begin{tabular}{|c|c|c|c|c|c|c|c|}
\hline \multicolumn{4}{|c|}{ PETTIT'S TEST } & \multicolumn{4}{|l|}{ SNHT } \\
\hline K-Value & Year & P-Value & $\mathrm{T}$ & To-Value & Year & P-Value & $\mathrm{T}$ \\
\hline 243 & 1969 & 0.624 & Ho & 9.39 & 2011 & 0.032 & $\mathrm{Ha}$ \\
\hline \multicolumn{4}{|c|}{ BUSHANDS TEST } & \multicolumn{3}{|c|}{ VON NEUMANNS } & \\
\hline Q-Value & $\mathrm{N}$ & P-Value & $\mathrm{T}$ & $\mathrm{N}$ & & P-Value & $\mathrm{T}$ \\
\hline 6.616 & 2011 & 0.369 & Ho & 1.42 & & 0.002 & $\mathrm{Ha}$ \\
\hline
\end{tabular}

We tested the above Hypotheses at a 0.05 significant level. When the p-value exceeds the significance level, the null hypothesis is not rejected because there is insufficient evidence to conclude that the data do not follow a normal distribution. The findings show that all three normality tests agree that the Rainfall series has a normal distribution. In parametric testing, the normal distribution assumption is crucial for accuracy. Using the statistical analysis program XLSTAT 2016, the homogeneity of the annual total rainfall was evaluated using the following four homogeneity tests: The Pettitt test Von Neumann's ratio (VNR) test, Buishand's test (BRT), and the standard normal homogeneity test (SNHT). Table 4 summarizes the results of the homogeneity tests. Homogeneous data is a term used to describe a homogeneous set of data. Ha, There is a point in time when the data changes. As the computed p-value is lower than the significance level alpha $=0.05$, one should reject the null hypothesis Ho and accept the alternate hypothesis Ha that the data is not homogeneous. The four homogeneity tests were in agreement that the data series is not homogeneous.

A homogeneous climate time series is one where the variations are caused only by variations in climate (Aguilar et al., 2003). Non-climatic factors may hide the true climatic signals and patterns and thus potentially bias the conclusions of climate and hydrological studies. Causes of inhomogeneity may include monitoring station relocations, changes in instrumentation, changes of the surroundings, instrumental inaccuracies, and changes of observational and calculation procedures. Unfortunately, few long-term climate time series are 
free of irregularities (Auer et al. 2005). The input data of CRU were homogenized. Hence the cause of noticed inhomogeneity may be due to climate variability. The plot of Homogeneity test showing no significant abrupt changes for rainfall and significant abrupt changes for temperature are presented in Fig 2 and 3 below:

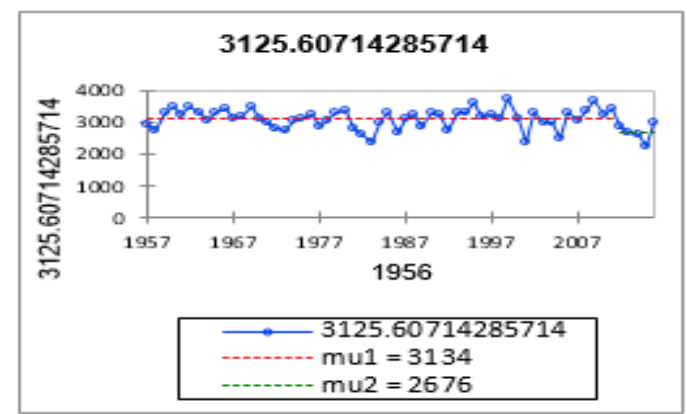

Figure 2 Homogeneity Plot showing no abrupt changes for Rainfall

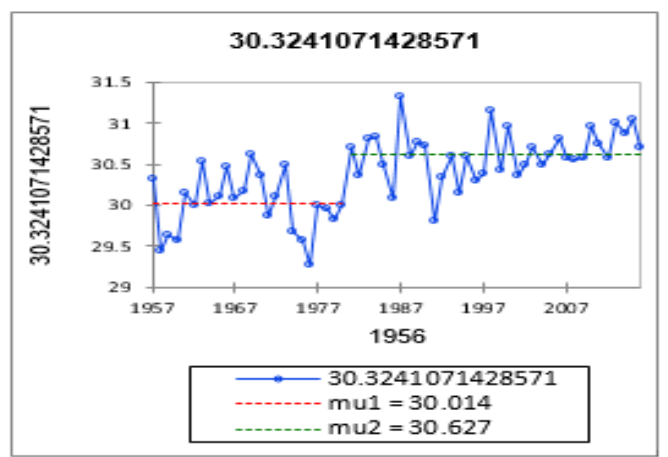

Fig 3 Homogeneity Plot showing abrupt changes for Temperature
The Durbin Watson was used to detect autocorrelation analysis. Table 5 shows the Results of the Durbin Watson' S Test conducted to detect autocorrelation.

Since the computed p-value is less than the significance level alpha $=0.05$, the null hypothesis $\mathrm{H} 0$ should be rejected, and the alternative hypothesis $\mathrm{Ha}$ that the residuals are autocorrelated should be accepted.

Regression analysis is a useful tool for testing trends when a serial correlation is low. The time series must be free of serial correlation before the MK test can be applied, as this can cause the actual result of the trends to be misled (Yue et al., 2002). Trend-Free PreWhitening (TFPW) was used in this study to remove serial correlation from a time series. This method has been used to remove serial correlation in various studies, such as Burn et al. (2004).

Detecting Heteroscedasticity: Breusch-Pagan \& White Test under Regression in XL Statistic software was used. The results are presented in Table 6 .

\begin{tabular}{|c|c|c|c|c|}
\hline DW & RHO & $\begin{array}{l}\text { P- } \\
\text { VALUE }\end{array}$ & ALPHA & $\begin{array}{l}\text { DECISION } \\
\text { (accept) }\end{array}$ \\
\hline 1.377 & 0.306 & 0.009 & 0.05 & $\mathrm{Ha}$ \\
\hline
\end{tabular}

Table 6 Results of Heteroscedasticity Test of Rainfall and Temperature

\begin{tabular}{lllllll}
\hline LM Observed & $\begin{array}{l}\text { LM } \\
\text { Critical }\end{array}$ & Df & $\begin{array}{l}\text { P-value } \\
\text { Two tail }\end{array}$ & Alpha & Decision \\
\hline Rainfall & 4.895 & 5.991 & 2 & 0.087 & 0.05 & Cannot Reject Ho \\
Temp. & 5.903 & 5.991 & 2 & 0.052 & 0.05 & Cannot Reject Ho \\
\hline \multicolumn{6}{c}{ HO: Residuals are homoscedastic: Ha: Residuals are heteroscedastic }
\end{tabular}

The null hypothesis $\mathrm{H} 0$ cannot be rejected because the computed $\mathrm{p}$-value is greater than the significance level alpha $=0.05$. As a result, the residual rainfall series exists. Homoscedastic. The spread of the residuals is assumed to be constant across the plot in linear regression. As a result, the Linear Regression Model can be used safely for further analysis.
Trend Series Analysis: The results of three trend detection tests carried out following the procedures of TREND software are presented in Tables 7 These tests are Mann-Kendal, Thei-Sen, Spearman's Rho, and Linear Regression. The plot of Linear Regression is presented in figures 1 (a) to(i) and Table7

Table 7 Summary of Trend Detection for Rainfall (1956-2016)

\begin{tabular}{|c|c|c|c|c|}
\hline TEST & \multicolumn{4}{|c|}{ TREND DETECTION AND MAGNITUDE OF TREND } \\
\hline STATISTIC & $\begin{array}{l}\text { Mann-Kendal } \\
\alpha=0.05\end{array}$ & $\begin{array}{l}\text { Thei-Sen } \\
\alpha=0.05\end{array}$ & $\begin{array}{l}\text { Spearman's Rho } \\
\alpha=0.05\end{array}$ & $\begin{array}{l}\text { Linear } \\
\text { Regression } \alpha=0.05\end{array}$ \\
\hline TEST STAT & -1.238 & -2.8276 & -1.198 & -1.348 \\
\hline Critical value & 645 & - & 1.645 & 1.672 \\
\hline Decision & \multicolumn{4}{|c|}{ Show no Significant TREND } \\
\hline
\end{tabular}




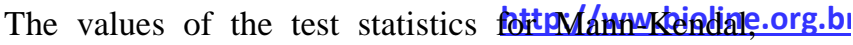
Spearman's Rho, and Linear Regression were in agreement as in Table 7 and indicated that there was no significant trend in annual rainfall. The Thei-Sen Slope test gave the magnitude of the trend to be $2.8276 \mathrm{~mm} /$ year.

The null hypothesis Ho: there is no trend in the data.

The alternate hypothesis Ha: there is a trend in the data

If the value is greater than the critical value, the null

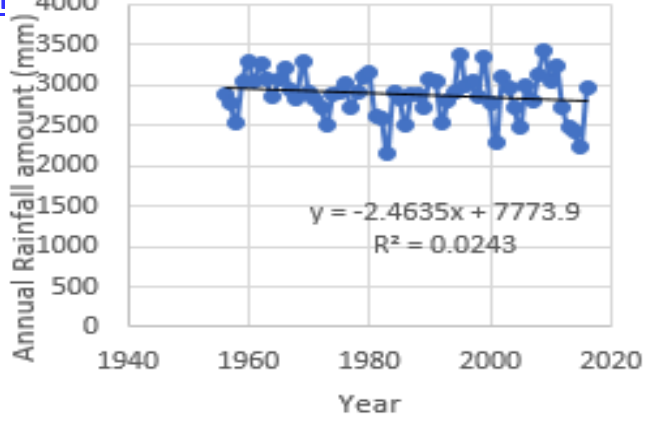
hypothesis is rejected. Accept the alternative hypothesis and assume there is no trend in the data. There is a trend in the data at the 0.05 significant level, indicating an increasing trend with an annual rate of 15.4 and $15.8 \mathrm{~mm}$, respectively and the $\mathrm{R}^{2}=0.5012$ and 0.5178 . For $\mathbf{0 . 5}<\mathbf{R}^{2} \leq \mathbf{0 . 6 5}$ as in the case above, $\mathbf{R}^{2}$ is satisfactory as 50 to $52 \%$ can be explained by a Linear regression line. Hence linear regression model can safely be used to model these series. We established the existence of trend and the magnitude of the trend using Mann-Kendal and Thei-Sen Slope test, which was implemented by XLSTAT Software. The results obtained from 25 locations are presented in Table 8 .

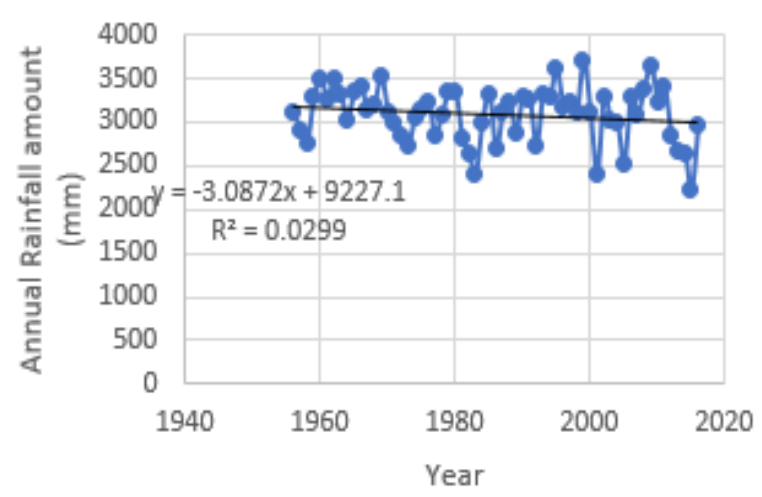

Fig.4. Annual rainfall spatial for Bayelsa

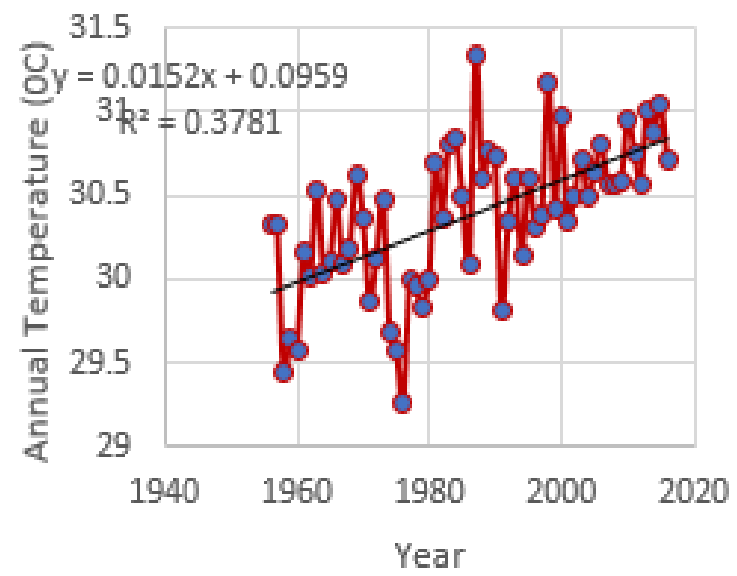

Fig. 5 Annual Temp. Spatial for Bayelsa

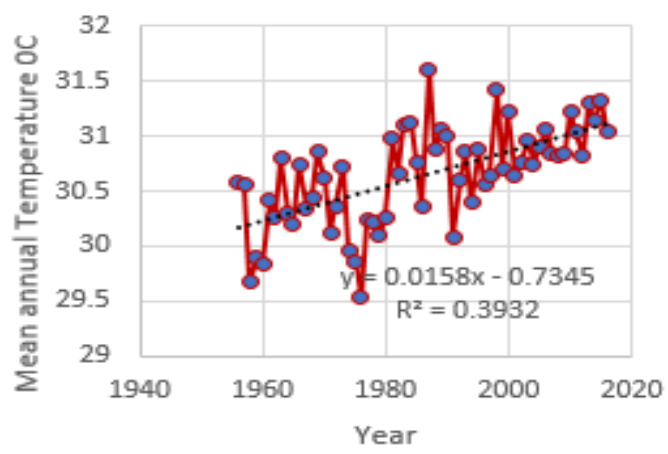

Fig 7. Trend analysis of Temp for Yenegoa

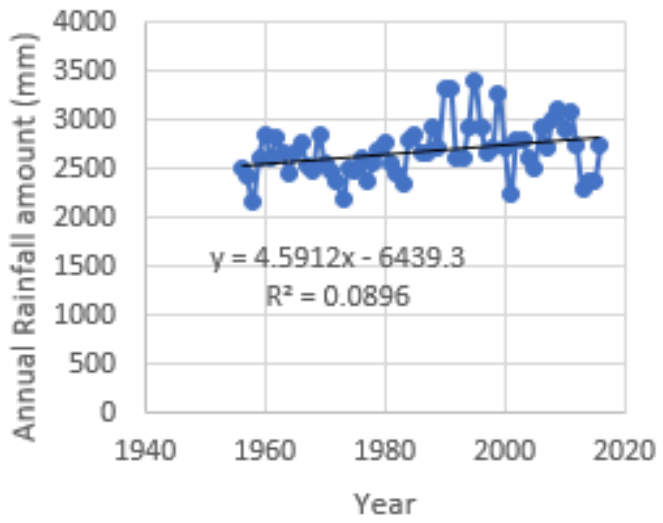

Fig .8 Trend analysis of rainfall for Kenan

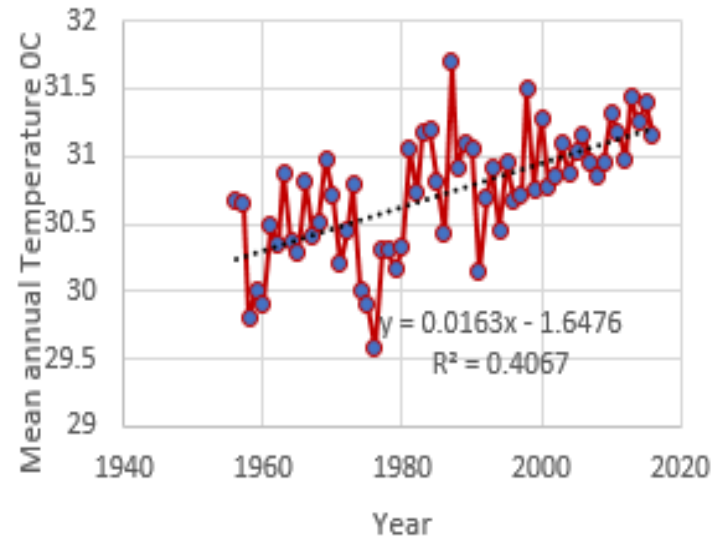

Fig.9 Trend analysis of rainfall for Kenan 
The results of Linear Regression Analysis of rainfall Trends obtained from 28 locations are presented in Table 9 Table 9: shows the result of the Linear Regression Analysis of rainfall and Temperature Trends. In 8 of the places, rainfall is growing insignificantly in varying magnitudes, whereas in 17 sites, rainfall is dropping in varying magnitudes. Table 9 depicts. In every site, the temperature rose significantly.

The Summary of the result of the Abrupt Change/Jump Detection test for rainfall (1956-2016) is presented in Table 10.

The null hypothesis Ho for the tests for step jump in mean/median is that there is no significant step jump in the mean/median. The alternative hypothesis Ha for the tests for step jump in mean/median is that there is a significant step jump in the mean/median.

We reject the null hypothesis Ho that there is no significant step jump in the mean/median and accept the alternate hypothesis Ha that there is a steep leap in the mean/median in the data at the 0.05 significant level if the test statistics is more than the critical value. level, we are unable to reject the null hypothesis Ho that there is no significant step leap in the mean/median.

Summary Test Statistics for differences in mean of Annual Rainfall and Temperature (1956-1986 and 1987-2016) is presented in Table 11.

For the test of difference in means/medians, the null hypothesis $\mathrm{H} 0$ states that there is no difference in means/medians between two data periods, while the alternative hypothesis $\mathrm{Ha}$ states that there is a difference in means/medians between two data periods.

If the test statistics are greater than the critical value, we reject the null hypothesis Ho, which states that there is no significant difference in the mean/median, and accept the alternate hypothesis $\mathrm{Ha}$, which states that there is a difference in the mean/median in the data at the 0.05 significant level.

The test results are greater than the crucial value in the example above. As a result, we reject Ho and embrace the alternative hypothesis.

The test results are smaller than the crucial value in the example above. As a result, at the 0.05 significant

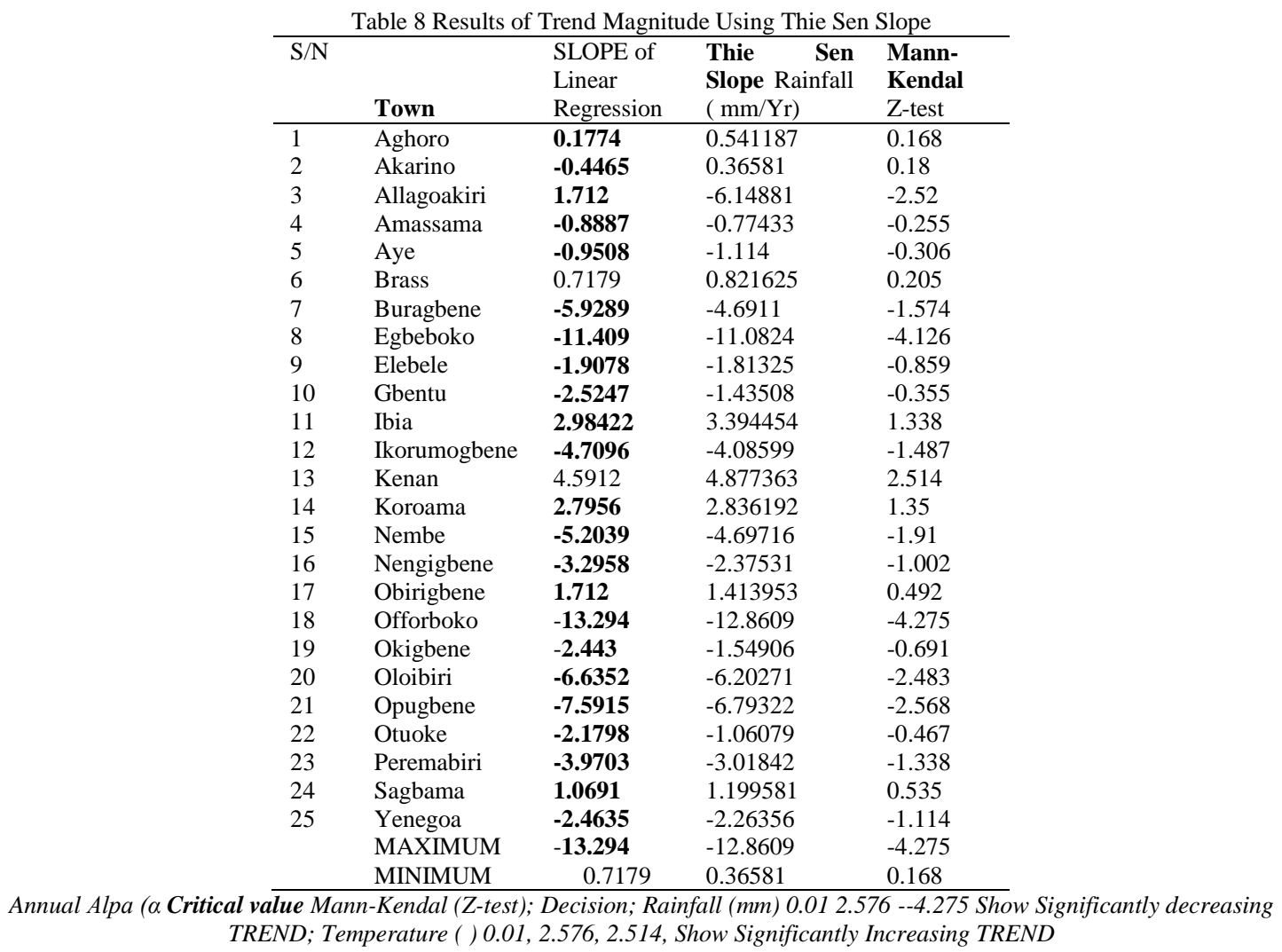


Table 9: Linear Regression Analysis of Rainfall and Temperature Trends

\begin{tabular}{|c|c|c|c|c|c|c|c|c|}
\hline Town & Equation & $\mathrm{R}^{2}$ & Slope & Nature & EQUATION & $\mathrm{R}^{2}$ & Slope & Nature \\
\hline Aghoro & $Y=0.1774 X+3113.4$ & 6E-05 & 0.1774 & Increasing & $Y=0.0145 X+1.3389$ & 0.3459 & 0.0145 & Increasing \\
\hline Akarino & $Y=-0.4465 X+4258$ & 0.0004 & -0.4465 & Increasing & $Y=0.0147 X+0.8487$ & 0.3563 & 0.0147 & Increasing \\
\hline Allagoakiri & $Y=1.712 X-275.8$ & 0.0089 & 1.712 & Increasing & $Y=0.016 X-11881$ & 0.3992 & 0.016 & Increasing \\
\hline Amassama & $Y=-0.8887 X+4784$ & 0.0028 & -0.8887 & Decreasing & $Y=0.0151 X+0.4384$ & 0.3702 & 0.016 & Increasing \\
\hline Aye & $Y=-0.9508 X+3767$ & 0.0042 & -0.9508 & Decreasing & $Y=0 . .0133 X+4.3716$ & 0.3018 & $0 . .0133$ & Increasing \\
\hline Brass & $Y=0.7179 X+2238.6$ & 0.0008 & 0.7179 & Increasing & $Y=0.0155 X-0.531$ & 0.3827 & 0.0155 & Increasing \\
\hline Buragbene & $Y=-5.9289 X+15101$ & 0.0574 & -5.9289 & Decreasing & $Y=\mathbf{0 . 0 1 4 6 X}+0.8403$ & 03525 & 0.0146 & Increasing \\
\hline Egbeboko & $Y=-\mathbf{1 1 . 4 0 9 X}+2568$ & 0.2865 & -11.409 & Decreasing & $Y=\mathbf{0 . 0 1 6 X}-1.3504$ & 0.4005 & 0.016 & Increasing \\
\hline Elebele & $Y=-1.9078 X+6740.5$ & 0.0132 & -1.9078 & Decreasing & $Y=\mathbf{0 . 0 1 5 5 X}-4255$ & 0.3875 & 0.0155 & Increasing \\
\hline Gbentu & $Y=-2.5247 X+8416$ & 0.0098 & -2.5247 & Decreasing & $Y=\mathbf{0 . 0 1 4 5 X}+1.1564$ & 0.3487 & 0.0145 & Increasing \\
\hline Ibia & $Y=\mathbf{2 . 9 8 4 2 2 X}-3056$ & 0.0337 & 2.98422 & Increasing & $Y=\mathbf{0 . 0 1 5 5 X}-0.283$ & 0.3807 & 0.0155 & Increasing \\
\hline Ikorumogbene & $Y=-4.7096 X+1265$ & 0.0536 & -4.7096 & Decreasing & $Y=\mathbf{0 . 0 1 5 2 X}+0.1731$ & 0.3764 & 0.0152 & Increasing \\
\hline kenan & $Y=4.5912 X-6439$ & 0.0896 & 4.5912 & Increasing & $Y=\mathbf{0 . 0 1 6 3 X}-1.6476$ & 0.4067 & 0.0163 & Increasing \\
\hline Koroama & $Y=\mathbf{2 . 7 9 5 6 X}-2658.6$ & 0.0289 & 2.7956 & Decreasing & $Y=-\mathbf{0 . 0 1 5 6 X}-0.444$ & 0.3835 & 0.0156 & Increasing \\
\hline Nembe & $Y=-5.2039 X+13494$ & 0.0698 & -5.2039 & Decreasing & $Y=\mathbf{0 . 0 1 5 7 X}-0.7384$ & 0.3905 & 0.0157 & Increasing \\
\hline Nengigbene & $Y=-3.2958 X+9748.7$ & 0.0302 & -3.2958 & Decreasing & $Y=\mathbf{0 . 0 1 5 2 X}+0.173$ & 0.3765 & 0.0152 & Increasing \\
\hline Obirigbene & $Y=1.712 X-275.8$ & 0.0089 & 1.712 & Increasing & $Y=\mathbf{0 . 0 1 4 8 X}+0.8679$ & 0.3576 & 0.0148 & Increasing \\
\hline Offorboko & $Y=-\mathbf{1 3 . 2 9 4 X}+29609$ & 0.2823 & -13.294 & Decreasing & $Y=\mathbf{0 . 0 1 5 9 X}-1.102$ & 0.3944 & 0.0159 & Increasing \\
\hline Okigbene & $Y=-2.443 X-8125.2$ & 0.156 & -2.443 & Decreasing & $Y=\mathbf{0 . 0 1 5 X}-0.6607$ & 0.368 & 0.015 & Increasing \\
\hline Oloibiri & $Y=-6.6352 X-16249$ & 0.122 & -6.6352 & Decreasing & $Y=\mathbf{0 . 0 1 5 4 X}-0.194$ & 0.382 & 0.0154 & Increasing \\
\hline Opugbene & $Y=-7.5915 X+18384$ & 0.1257 & -7.5915 & Decreasing & $Y=\mathbf{0 . 0 1 4 7 X}+0.8948$ & 0.3621 & 0.0147 & Increasing \\
\hline Otuoke & $Y=-2.1798 X+7321.9$ & 0.0149 & -2.1798 & Decreasing & $Y=\mathbf{0 . 0 1 5 6 X}+0.5539$ & 0.3876 & 0.0156 & Increasing \\
\hline Peremabiri & $Y=-3.9703 X+11160$ & 0.0385 & -3.9703 & Decreasing & $Y=\mathbf{0 . 0 1 5 1 X}+0.2862$ & 0.3725 & 0.0151 & Increasing \\
\hline Sagbama & $Y=1.0691 X+738.42$ & 0.0044 & 1.0691 & Increasing & $Y=\mathbf{0 . 0 1 5 8} X+0.8619$ & 0.3929 & 0.0158 & Increasing \\
\hline Yenegoa & $Y=-\mathbf{2 . 4 6 3 5 X}+0.8948$ & 0.0243 & -2.4635 & Decreasing & $Y=\mathbf{0 . 0 1 5 8 X}+0.7345$ & 0.3932 & 0.0158 & Increasing \\
\hline
\end{tabular}

Table 10 (a) Summary of Abrupt Change/Jump Detection for Rainfall (1956-2016)

\begin{tabular}{llll}
\hline TEST & ABRUPT & CHANGE/JUMP DETECTION \\
\hline STATISTIC & CUSUM & Cumulative deviation & Worsley Likelihood \\
TEST STAT & 6 & 0.855 & 3.343 \\
Critical value & $\mathbf{9 . 5 2 9}$ & $\mathbf{1 . 1 4 7}$ & $\mathbf{2 . 8 7}$ \\
Decision & No Significant Step Jump & \\
\hline
\end{tabular}

Table 10 (b) Summary of Abrupt Change/Jump Detection for Rainfall and Temp. (1956-2016)

\begin{tabular}{llll}
\hline \multicolumn{4}{c}{ CHANGE DETECTION ANALYSIS OF ANNUAL } \\
\hline RAINFALL & TEMP & \\
\hline Show no statistically Significant Step Jump & Show statistically Significant Step Jump in & 1980 \\
\hline
\end{tabular}

Table 11 Summary Test Statistics for differences in mean of Annual Rainfall and Temperature (1956-1986 and 1987-2016)

\begin{tabular}{|c|c|c|c|c|}
\hline Test Statistics & \multicolumn{2}{|c|}{ Rank Sum Z-stat } & \multirow{2}{*}{$\begin{array}{l}\text { Student ' } t \text { ' } \\
\text { Rainfall }\end{array}$} & \multirow{2}{*}{$\begin{array}{l}\text { (t-test) } \\
\text { Temperature }\end{array}$} \\
\hline & Rainfall & Temperature & & \\
\hline Test Stat & 0.353 & -4.407 & -4.432 & $\infty$ \\
\hline Critical value & 1.645 & 2.576 & 1.671 & 2.66 \\
\hline Decision & \multicolumn{4}{|c|}{$\begin{array}{l}\text { Significantly Different; Increasing and decreasing } \\
\text { rainfall } \\
\text { Significantly Different; Increasing Temperature }\end{array}$} \\
\hline
\end{tabular}

Table 12 Student's T-test for Differences in mean annual rainfall during the two climatic periods (Student t-test)

\begin{tabular}{llllll}
\hline Mean 1 & 274.493 & Variance 2 & $25,129.85$ & df & 11 \\
\hline Mean 2 & 276.182 & Observations & 12 & t Stat & -2.3489 \\
Variance 1 & $25,472.16$ & Pearson Correlation & 0.984261 & $\mathrm{P}(\mathrm{T}<=\mathrm{t})$ one-tail & 0.019281 \\
\hline
\end{tabular}

Table 13: Percentage variation in Annual rainfall $(\mathrm{mm})$ pattern Percentage variation in Annual

\begin{tabular}{llll}
\multicolumn{3}{c}{ Table 13: Percentage variation in Annual rainfall $(\mathrm{mm})$ pattern Percentage variation in Annual } \\
\hline & Annual rainfall & & Temp. $\left({ }^{0} \mathrm{C}\right)$ pattern \\
\hline First Climatic Year & 3072.692 & First Climatic Year & 361.7617 \\
Second Climatic Year & 3075.504 & Second Climatic Year & 367.6732 \\
Change & 2.812 & Change & 5.9115 \\
$\%$ Change & 0.092 & \% Change & 1.634 \\
\hline
\end{tabular}

Table 14 Variability of Spatial of Mean Annual Rainfall and Temperature Data

\begin{tabular}{llllll}
\hline MEAN(Rm) & SD & CV (\%) & MEAN(Tm) & SD & CV (\%) \\
\hline 256.17 & 160.73 & 62.74 & 30.393 & 1.324 & 4.356 \\
\hline
\end{tabular}

According to Hare (2003), CV is used to classify the as low $(\mathrm{CV}<20)$, moderate $(20<\mathrm{CV}<30)$, high $(\mathrm{CV}$ degree of variability of rainfall and temperature events $>30$ ), very high $\mathrm{CV}>40 \%$ and $\mathrm{CV}>70 \%$ indicate 
extremely high inter-annual variability of rainfall. The coefficient of variation (CV) between 62.74 indicated a very high variability of precipitation over the state. The coefficient of variation (CV) for temperature is $4.356 \%$ indicated low variability. This study has established that there is very strong evidence of climate variability and climate change. The decadal variability for rainfall for the period under consideration (1956-2015) is presented in Table 15. The decadal mean and percentage changes are also contained in Table15 accordingly. The table shows the decadal variability of the rainfall, the decadal mean,

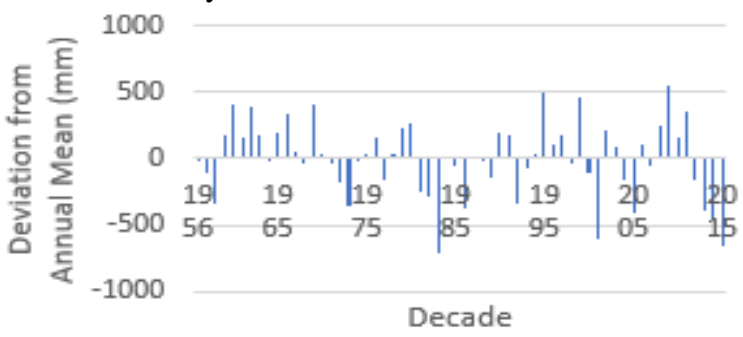

and percentage changes in the rainfall accordingly. The positive sign signifies much rainfall (wet), while the negative sign signifies less rainfall (dry) for the particular decade under consideration. It was discovered that three decades (1976-1985, 1996-2005, and 2006-2015) accounted for 50 percent of total rainfall, while the remaining decade (1986-1995) accounted for $16.7 \%$ of total rainfall. The representative plot of deviation from annual mean against decades is presented in Figure 10 for rainfall and temperature for Yenegoa.

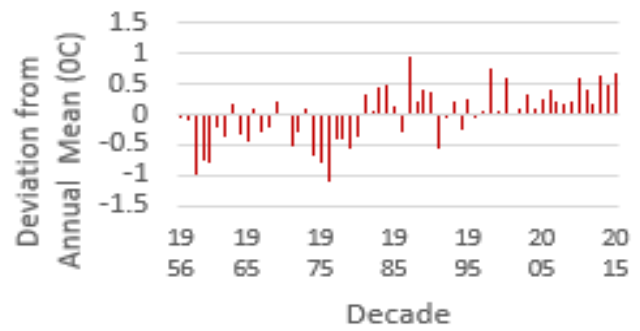

Fig. 10 Decadal Deviation from mean of rainfall and temperature for Yenegoa

Table 15 Percentage of Decadal Deviation from Mean Rainfall. State: Bayelsa

\begin{tabular}{|c|c|c|c|c|c|c|c|}
\hline $\mathbf{S} / \mathbf{N}$ & TOWN & 1956-1965 & 1966-1975 & 1976-1985 & 1986-1995 & 1996-2005 & 2006-2015 \\
\hline 1 & Aghoro & 0.0831 & -0.1369 & -0.7790 & 0.9620 & 0.9620 & 0.0658 \\
\hline 2 & Akarino & 0.0567 & -0.2190 & -0.5330 & 1.1258 & -0.1647 & -0.0839 \\
\hline 3 & Aleibri & 0.0423 & -0.0002 & 0.1938 & 0.4452 & -0.2539 & -0.3562 \\
\hline 4 & Allagoakiri & 1.3337 & 0.6754 & -0.5079 & -1.1174 & 0.0118 & -0.4477 \\
\hline 5 & Amassama & 0.2157 & -0.2405 & -0.5027 & 0.6500 & -0.0289 & -0.1626 \\
\hline 6 & Aye & 0.6273 & 0.2077 & -0.9501 & 0.2151 & -0.4952 & 0.4426 \\
\hline 7 & Brass & 0.3536 & -0.2740 & -0.8249 & 0.1885 & 0.2738 & 0.28277 \\
\hline 8 & Buragbene & 0.6358 & 0.2355 & -0.2607 & 1.0192 & -0.5568 & -0.8054 \\
\hline 9 & Egbeboko & 1.9334 & 1.1543 & -0.1109 & -1.0672 & -0.9744 & -0.8529 \\
\hline 10 & Elebele & 0.4951 & 0.0224 & -0.3005 & -0.0177 & -0.1207 & -0.1246 \\
\hline 11 & Gbentu & 0.2767 & -0.0230 & -0.6176 & 1.1844 & -0.1644 & -0.3278 \\
\hline 12 & Ibia & -0.3134 & -0.6570 & -0.6246 & 1.1507 & 0.1263 & 0.3480 \\
\hline 13 & Ikorumogbene & 0.7395 & 0.2356 & -0.3023 & 0.0920 & -0.2353 & -0.4331 \\
\hline 14 & kenan & -0.6379 & -0.9776 & -0.5315 & 1.4315 & 0.2660 & 0.4197 \\
\hline 15 & Koroama & -0.1594 & -0.5232 & -0.6409 & 0.6687 & 0.1822 & 0.4249 \\
\hline 16 & Nembe & 0.0462 & -0.2675 & 0.4669 & -0.2575 & -0.4889 & -0.3089 \\
\hline 17 & Nengigbene & 0.5109 & 0.0462 & -0.2675 & 0.4669 & -0.2575 & -0.4889 \\
\hline 18 & Obirigbene & -0.0460 & -0.3082 & -0.7226 & 0.9125 & -0.0684 & 0.3044 \\
\hline 19 & Offorboko & 2.0077 & 1.2054 & -0.2867 & -0.7842 & -0.9443 & -1.0451 \\
\hline 20 & Okigbene & 0.1044 & 0.0222 & 0.1642 & 0.2268 & -0.3333 & -0.4992 \\
\hline 21 & Oloibiri & 0.9755 & 0.4477 & -0.0880 & 0.0418 & -0.4597 & -0.9000 \\
\hline 22 & Opugbene & 0.1523 & 0.1042 & 0.0629 & 0.1897 & 0.0629 & -0.1600 \\
\hline 23 & Otokolopiri & 0.3536 & -0.2740 & -0.8249 & 0.18856 & 0.2738 & 0.2827 \\
\hline 24 & Otuoke & 0.5105 & 0.0235 & -0.1728 & -0.5557 & 0.3393 & -0.1783 \\
\hline 25 & Peremabiri & 0.6497 & 0.1612 & -0.4696 & 0.3374 & -0.2170 & -0.4256 \\
\hline 26 & Sagbama & -0.0619 & -0.3822 & -0.6304 & 1.0769 & -0.0404 & 0.0782 \\
\hline \multirow[t]{4}{*}{27} & Yenegoa & 0.5811 & 0.1555 & -0.4331 & -0.0225 & -0.1544 & -0.1750 \\
\hline & Total & 11.4662 & 0.4135 & -10.4944 & 8.75146 & -3.4601 & -5.12613 \\
\hline & Mean & 0.4246 & 0.0153 & -0.3886 & 0.3241 & -0.1281 & -0.18985 \\
\hline & MAX & 2.0077 & 1.2054 & -0.9501 & 1.4315 & -0.9744 & -1.0451 \\
\hline
\end{tabular}

The magnitude of trend analysis of decadal rainfall using theil sen' slope analysis ( $\mathrm{mm} /$ decade) is presented in Table.17.

The result of the comparison of the mean seasonal Rainfall and Temperature pattern: Figure 11 shows the results for the twelve months of the year for two climatic eras (1956-1986 and 1987-2016). Fig11 (a) \& (b) Mean Annual Seasonal Distribution of rainfall and temperature for Bayelsa. Figure 11 shows the comparison of the mean seasonal Rainfall and Temperature pattern for two climatic periods for the 
twelve months of the year. It indicated that July recorded the highest rainfall for the first and second climatic years. The least rainfall happened in January and December for the two climatic periods.

TABLE 16 Percentage Of Decadal Deviation From Mean Temperature. State: Bayelsa

\begin{tabular}{|c|c|c|c|c|c|c|c|}
\hline $\mathbf{S} / \mathbf{N}$ & TOWN & 1956-1965 & 1966-1975 & 1976-1985 & 1986-1995 & 1996-2005 & 2006-2015 \\
\hline 1 & Aghoro & -10.9616 & -8.22642 & -4.90797 & 4.13849 & 6.47984 & 12.54154 \\
\hline 2 & Akarino & -11.5719 & -7.94546 & -4.87271 & 4.042873 & 6.739139 & 12.62257 \\
\hline 3 & Aleibri & -11.7259 & -8.07306 & -4.85743 & 4.054735 & 6.755502 & 12.73237 \\
\hline 4 & allagoakiri & -12.67 & -7.28464 & -5.81253 & 3.612561 & 7.63631 & 13.43385 \\
\hline 5 & Amassama & -11.6286 & -8.02028 & -4.79024 & 3.834164 & 6.704707 & 12.70128 \\
\hline 6 & aye & -6.05925 & -9.96964 & -6.73143 & 2.331976 & 6.158467 & 12.48198 \\
\hline 7 & Brass & -13.8396 & -6.48365 & -5.10988 & 4.323395 & 7.525215 & 12.55691 \\
\hline 8 & buragbene & -11.8572 & -7.75517 & -4.79541 & 4.19555 & 6.701106 & 12.65599 \\
\hline 9 & Egbeboko & -12.7949 & -7.05641 & -6.18272 & 3.71541 & 7.90546 & 13.33869 \\
\hline 10 & elebele & -12.4621 & -7.79064 & -4.80816 & 4.108286 & 6.73506 & 13.00466 \\
\hline 11 & forupa & -12.4079 & -7.43636 & -4.78841 & 4.305675 & 6.933186 & 12.23232 \\
\hline 12 & Gbentu & -11.3839 & -8.02768 & -4.88395 & 4.367336 & 6.435336 & 12.69869 \\
\hline 13 & ibia & -11.6109 & -8.29637 & -5.05373 & 3.578788 & 6.894095 & 13.14867 \\
\hline 14 & Ikorumogbene & -12.5022 & -7.39886 & -4.81597 & 4.125248 & 6.924301 & 12.63232 \\
\hline 15 & kenan & -12.3371 & -8.13402 & -5.2864 & 3.486072 & 7.418496 & 13.6706 \\
\hline 16 & Koroama & -12.0018 & -8.20332 & -4.84426 & 3.896582 & 6.654835 & 13.20728 \\
\hline 17 & nembe & -12.8656 & -7.5816 & -5.38313 & 3.879784 & 7.355199 & 13.13178 \\
\hline 18 & Nengigbene & -12.363 & -7.58657 & -4.70874 & 4.100162 & 6.727667 & 12.72269 \\
\hline 19 & Obirigbene & -11.6845 & -7.88734 & -4.69762 & 4.042944 & 6.574555 & 12.62585 \\
\hline 20 & Offorboko & -12.9134 & -6.58174 & -6.22625 & 3.679951 & 7.70332 & 13.35281 \\
\hline 21 & okigbene & -11.9391 & -7.47978 & -4.81865 & 3.921938 & 6.672689 & 12.60217 \\
\hline 22 & Oloibiri & -12.5229 & -7.64373 & -4.63003 & 3.972712 & 6.823855 & 12.84943 \\
\hline 23 & Opugbene & -11.8463 & -7.51855 & -4.949 & 4.104287 & 6.876453 & 12.45763 \\
\hline 24 & otokolopiri & -13.125 & -6.73341 & -5.47694 & 4.270713 & 7.450128 & 12.71455 \\
\hline 25 & Otuoke & -12.4631 & -7.77606 & -4.92699 & 3.92348 & 6.97347 & 13.04423 \\
\hline 26 & peremabiri & -12.2517 & -7.56782 & -4.78951 & 4.016701 & 6.905037 & 12.65053 \\
\hline 27 & sagbama & -12.5008 & -8.19485 & -4.75705 & 4.068458 & 6.88236 & 13.16862 \\
\hline \multirow[t]{3}{*}{28} & yenegoa & -12.7649 & -7.82063 & -4.77497 & 4.222433 & 6.860195 & 12.98234 \\
\hline & MEAN & -12.03768 & -7.73122 & -5.09572 & 3.940025 & 6.943071 & 12.8558 \\
\hline & TOTAL & -337.05515 & -216.47406 & -142.68008 & 110.320704 & 194.405983 & 359.96235 \\
\hline
\end{tabular}

Table 17: Magnitude Of Trend Analysis of Decadal Rainfall and Temperature Using Theil Sen' Slope Analysis (mm/decade)

\begin{tabular}{llllllll}
\hline $\mathbf{S} / \mathbf{N}$ & & $\mathbf{1 9 5 6 - 1 9 6 5}$ & $\mathbf{1 9 6 6 - 1 9 7 5}$ & $\mathbf{1 9 7 6 - 1 9 8 5}$ & $\mathbf{1 9 8 6 - 1 9 9 5}$ & $\mathbf{1 9 9 6 - 2 0 0 5}$ & $\mathbf{2 0 0 6 - 2 0 1 5}$ \\
\hline 1 & Rainfall & 24.4 & -58.2 & $\mathbf{- 1 4 . 0 8}$ & $\mathbf{6 1}$ & -34 & -44.55 \\
2 & Temperature & 0.06567 & -0.0741 & $\mathbf{0 . 1 0 9 3}$ & $\mathbf{- 0 . 0 1 7 2 3}$ & 0.1093 & 0.02189 \\
\hline
\end{tabular}
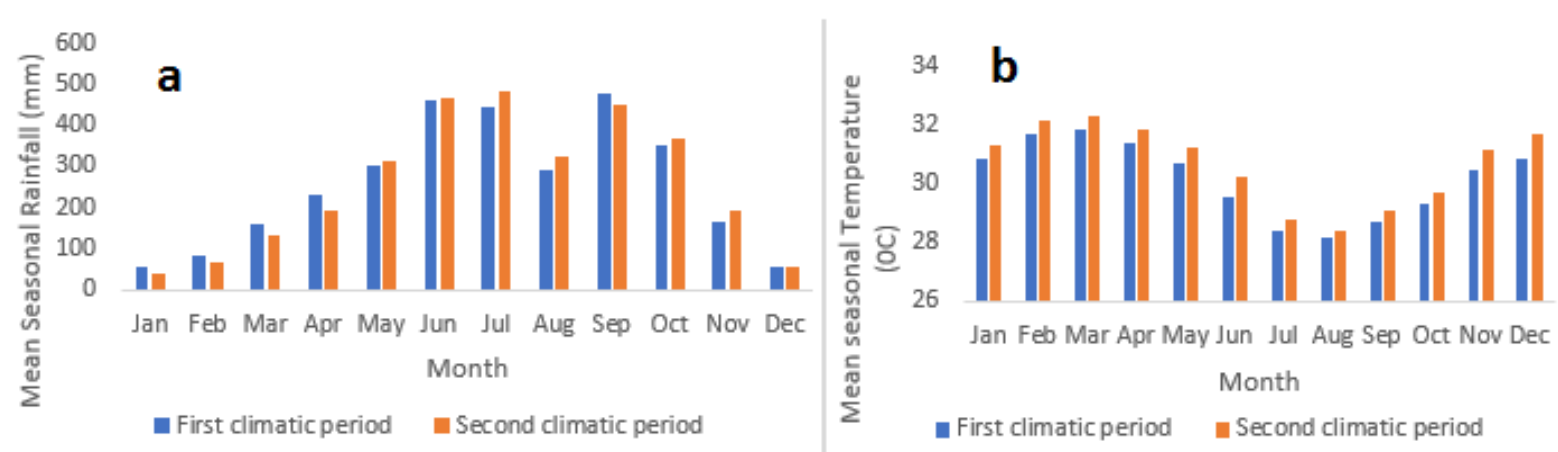

Fig 11 shows the results for the twelve months of the year for two climatic eras (1956-1986 and 1987-2016).

Spectral analysis: Spectral analysis of the time series is used to detect a cyclic component of the time series both with high and low frequency. The result of Spectral analysis is presented in Figures 12 to 13 The Rainfall output of spectral analysis showed that the test STATISTIC Fisher's Kappa was 4.699, the P-Value was 0.207 , and the most significant Periodicity was 15years. Also, The Temperature output of spectral analysis showed that the test STATISTIC Fisher's
Kappa was 7.618, the P-Value was 0.006, and the most significant Periodicity was 15 years.

Conclusion: Statistical evidence has shown that there had been changes in Temperature data which displayed a significantly increasing trend. There has been rainfall fluctuation which has implications for coastal flooding, quality, and quantity of available groundwater in the state. The results of this research 
are useful to planners and policymakers in creating awareness of climate change's impact on rainfall in the study area. By identifying system vulnerabilities and weighing mitigation strategies, this analysis will aid policymakers in making sound decisions.

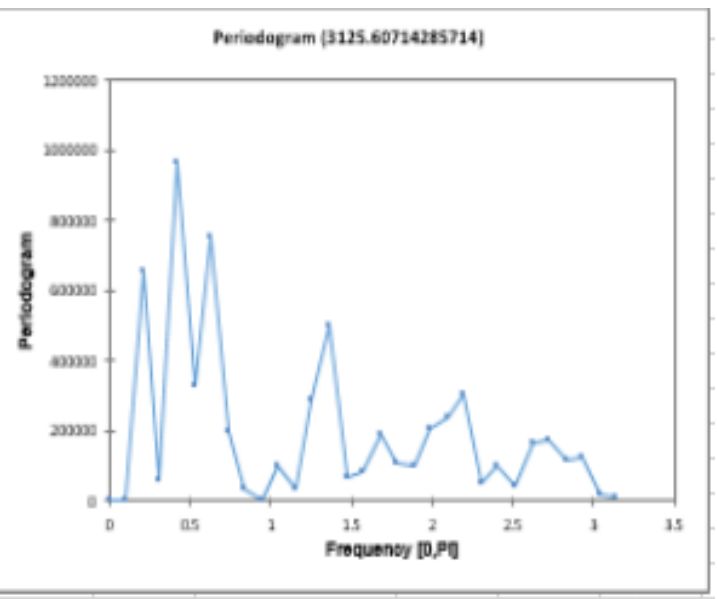

Fig 12 (a) Rainfall Output of spectral analysis

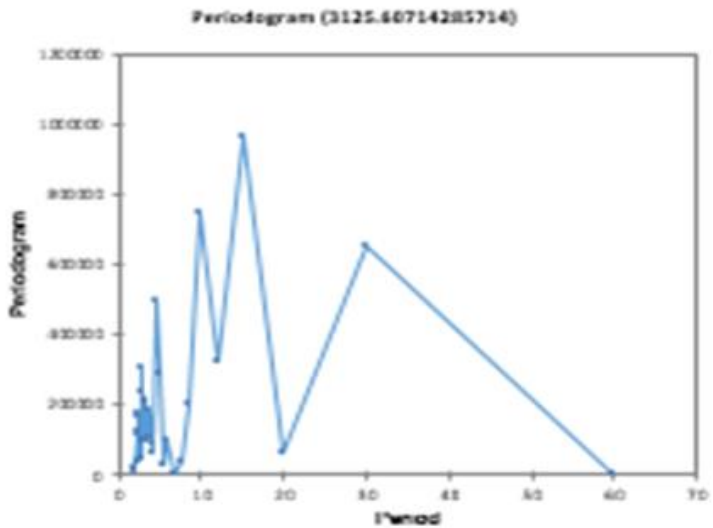

Fig 12(b) Rainfall Periodogram Period Curve for

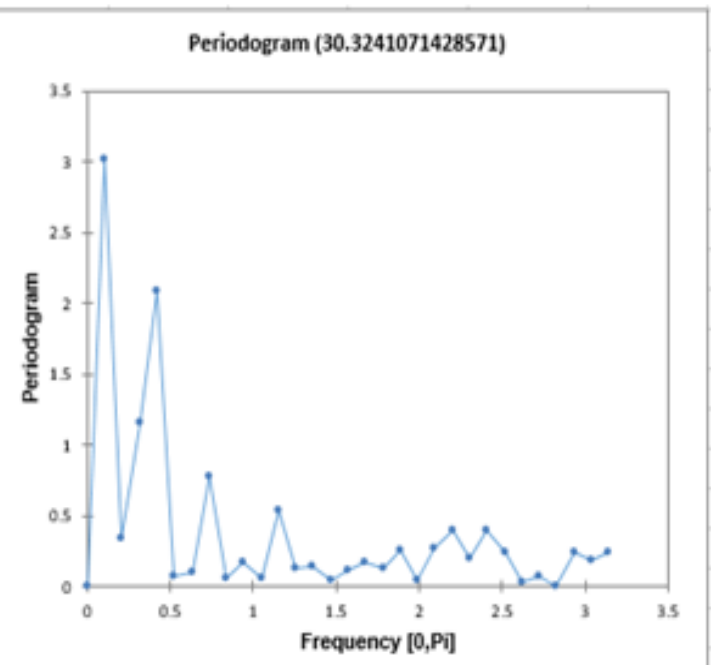

Fig 13 (a) Temp output of spectral analysis

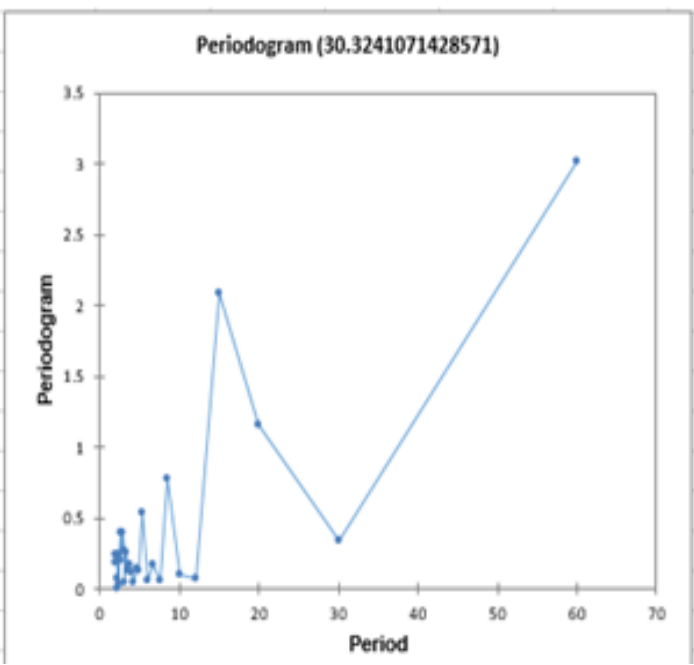

Fig13 (b) Temp. the output of the spectral analysis

\section{REFERENCES}

Aguilar, E; Auer, I; Brunet, M; Peterson, T.C; Wieringa, J (2003) Guidelines on climate metadata and homogenization. World Meteorological Organization, WMO-TD No. 1186, WCDMP No. 53, Geneva, Switzerland, 55 -

Burn, D H; Elnur, M A. (2002) Detection of hydrologic trends and variability. J Hydro; 255: 107-22

Ekpenyong, N S; Tonbra, O (2015) Adapting to Climate Change - Building Capacities for Flood Risk Management in Bayelsa State, Nigeria. International J. Sci. Res. Pub. 5 (3). 1-22

Hinkel, J; Brown, S; Exner, L; Nicholls, R.J; Vafeidis, A T; Kebede, A.S., (2011), 'Sea-level rise impacts on Africa and the effects of mitigation and adaptation: an application of DIVA', Reg. Environ. Change 12(1) 207-224.

Machiwal , D; Jha, MK (2012) Hydrologic time series analysis: theory and practice. Springer, the Netherlands and Capital Publishing Company, New Delhi, pp 70

McCuen, R.H. (2003) Modeling Hydrologic Change, Statistical Methods; CRC Press Company, Ed.; Lewis Publishers: Boca Raton, FL, USA., pp 149 $-151$

Mu, X; Zhang, L; McVicar, T. R; Chille, B; Gau, P. (2007): Analysis of the impact of conservation measures on streamflow regime in catchments of the Loess Plateau, China. Hydrological Processes. 21. 2124-2134 
Mundia S.M; Gichuhi, A.W; Kihoro, J M (2014). The Power of Likelihood Ratio Test for A Change Point in Binomial Distribution. J. Agric. Sci. Tech. 16 (3) 105-123

National Population Census-NPC. (2021), Bayelsa State Population Census, National Population Census, Federal Republic of Nigeria.

Olasupo, O.P; Ojo, R.I; Olaniran, J M (2017): Effects of Variations in Sea and Land Surface Temperature on Rainfall Pattern over Nigerian Coastal Zone. J. Environ. Earth Sci.7 (10) 40-50
Yue, S; Hashino, M. (, 2003). Long-term trends of annual and monthly precipitation in Japan. J. Am. Wat. Res. Assoc. 39(3), 587-596

Zsamboky, M; Fernández-Bilbao, A; Smith, D; Knight, J; Allan, J (2011) Impacts of Climate Change on Disadvantaged UK Coastal Communities. Published by the Joseph Rowntee Foundation, www.jrf.org.uk, ISBN: 978-185935-804-7 (pdf) Pp 21-33 